\title{
Del pasado al futuro: cambio de agendas en la educación docente entre los siglos XIX y XXI
}

\author{
From the Past to the Future: \\ Changing Agendas in Teacher Education \\ between the $19^{\text {th }}$ and the $21^{\text {st }}$ Century
}

\section{Du passé à I'avenir : Les ordres du jour changeants dans l'éducation des enseignants entre le $19^{\mathrm{e}}$ et le $21^{\mathrm{e}}$ siècle}

\author{
Anne Rohstock \\ University of Luxembourg, Luxemburgo

\section{Daniel Tröhler} \\ University of Luxembourg, Luxemburgo
}

\section{RESUMEN}

El cambio en la visión de la educación a fines del siglo dieciocho, la construcción de la nación en el siglo diecinueve, y los esfuerzos por promover una unidad global después de las dos Guerras Mundiales tuvieron efectos no sólo en las organizaciones educacionales, sus políticas, y materiales, sino también en la manera en que los mayores actores en el mundo de la educación - principalmente, maestros y profesores, fueron preparados. Las diferencias en los ideales y agendas de los programas de formación de maestros reflejan las principales preocupaciones culturales de cada era: en el siglo diecinueve dominaba el interés por la supremacía y el cultivo de lo que era nacionalmente distintivo, y en el período de pos-guerras, se centró en la internacionalización y la estandarización. Estas visiones estaban asociadas con la emergencia de sub-campos académicos que moldearon fuertemente los ideales pedagógicos. En la era de construcción de la nación, la historia de la educación dominaba la educación de maestros y profesores. En el contexto de la Guerra Fría, la formación de maestros y profesores estaba alineada con un nuevo paradigma científico e internacionalista. El artículo discute estas dos agendas 
en la formación de maestros. En la primera parte, reconstruimos el ascenso de historia de la educación como una materia central en los programas de inspiración nacionalista y religiosa en Francia y Alemania. En la segunda parte, mostramos cómo el leitmotiv en la Guerra Fría fue remplazado por un "giro cognitivo" en la formación del magisterio primario y secundario.

Descriptores: Psicología cognitiva; cibernética; Francia; Alemania; historias de la educación; internacionalización; meta cognición; construcción de la nación; ideales pedagógicos; nación Sagrada; cientifización; educación de maestros y profesores.

\section{ABSTRACT}

The educational turn of the late eighteenth century, nation building of the nineteenth century, and efforts to promote global unity after the two World Wars did not only have effects on educational organizations, policies, and materials, but also on the manner with which the major actors in the world of education - namely, teachers - were trained. The different ideals and agendas in teacher training reflected the major cultural concerns of each era: in the nineteenth century, this was national uniqueness and supremacy, which, in the post war period, gave way to internationalization and global standardization. These visions were associated with the emergence of particular academic subfields and heavily shaped pedagogical ideals. In the era of nation building, the history of education dominated teacher education. In the context of the Cold War teacher training was aligned with a new internationalist and scientific paradigm. The following chapter discusses these two agendas in teacher education. In the first section we will reconstruct the rise of the history of education as a major subject in nationalist and religiously inspired teacher education in Germany and France. In the second section we will show how this leitmotif in the Cold War era was supplanted by a "cognitive turn" in the training of professional educators.

Key words: Cognitive psychology; cybernetics; France; Germany; histories of education; internationalization; metacognition; nation-building; pedagogical ideals; sacred nation; scientification; teacher education.

\section{RÉSUMÉ}

Le tournant éducatif vers la fin du $18^{\mathrm{e}}$ siècle, l'émergence des nations au $19^{\mathrm{e}}$ siècle et les efforts pour promouvoir l'unité dans le monde après les deux guerres mondiales n'ont pas seulement eu une influence sur les organisations éducatives, les politiques et les matériaux, mais aussi sur la manière dont les principaux acteurs dans le monde de l'éducation—nommément les enseignants - ont été formés. Les différents idéaux et ordres du jour dans la formation des enseignants reflétaient les soucis culturels majeurs de chaque époque: au $19^{\mathrm{e}}$ siècle, c'étaient l'unicité nationale et la suprématie, qui à l'après-guerre ont cédé la place à l'internationalisation et la standardisation globale. Ces visions étaient associées à l'émergence de sous-terrains académiques particuliers et d'idéaux pédagogiques fortement structurés. Durant l'ère de l'émergence des nations, l'histoire de l'éducation dominait l'éducation des enseignants. Dans le contexte de la Guerre Froide, l'éducation des enseignants s'enlignait avec un nouveau paradigme internationaliste et scientifique. Le chapitre suivant discute des deux programmes en éducation des enseignants. Dans la première partie, nous reconstruirons la montée de l'histoire de l'éducation comme sujet majeur dans l'éducation des enseignants inspirée par le nationalisme et la religion en Allemagne et en France. Dans la seconde partie, nous montrerons comment, durant la Guerre Froide, ce leitmotiv a été supplanté par un «tournant cognitif» dans la formation des éducateurs professionnels.

Mots clés : La psychologie cognitive; la cybernétique; la France, I'Allemagne; les histoires de l'éducation; I'internationalisation; la métacognition; la nation-building; les idéaux pédagogiques; la nation sacrée; la scientification; I'éducation des enseignants. 


\section{Introducción}

$\mathrm{E}^{\mathrm{t}}$ LEGAdo más Significativo del CAmbio educacional del siglo XVIII fue el establecimiento del sistema escolar masivo moderno, un desarrollo relacionado con la abolición de las sociedades feudales y divididas de la época del Absolutismo y con el alza del Estado-nación moderno alrededor de 1800. La construcción de la nación y la creación del ciudadano moderno en gran medida fueron consideradas un proyecto educacional (Tröhler, Popkewitz, Labaree, 2011) en cuyo contexto surgió la educación como una disciplina académica (Lagemann, 2000).

Las guerras mundiales del siglo XX llevaron a cuestionar las nociones tradicionales del Estado — nación — y dieron pie a nuevas instituciones para ordenar la vida social y política, incluida la Liga de las Naciones después de la 1ª Guerra Mundial (Fuchs, 2006), además de las Naciones Unidas y otras organizaciones de gobierno global después de la 2a Guerra Mundial (Chabbott, 2003). De igual manera, la Guerra Fría motivó nuevos proyectos educacionales en el mundo occidental (Hartman, 2008; Tröhler, 2010). Luego de la 2a Guerra Mundial, la paz mundial pronto se conectó con un sentido transnacional de la ciudadanía. Más aún, en el contexto de la competencia con la Unión Soviética se asignó mayor énfasis a la ciencia (Rudolph, 2002) y las matemáticas (Erickson, 2006) en el currículo educacional.

El cambio educacional de fines del siglo XVIII, la construcción de la nación durante el siglo XIX y los esfuerzos para promover la unidad global después de las Guerras Mundiales no sólo tuvieron efectos sobre las organizaciones, las políticas y los materiales educacionales, sino también sobre la manera en que los actores principales de la educación, es decir los profesores, eran formados. Los distintos ideales y agendas en la educación de docentes reflejaban las mayores preocupaciones de cada era: en el siglo XIX se trató de la singularidad y supremacía nacional, que, en el período de postguerra, dio paso a la internacionalización y la estandarización global. Estas visiones estaban asociadas con la aparición de sub-áreas académicas específicas e ideales pedagógicos marcadamente definidos. En la era de la construcción nacional, la historia de la educación dominó la educación docente, mientras que en el contexto de la Guerra Fría esta estuvo alineada con el nuevo paradigma internacionalista y científico.

El siguiente capítulo analiza estos dos programas de formación docente, los que deben ser considerados adecuadamente como reflejos de las aspiraciones políticas y culturales predominantes de su tiempo. En la primera sección reconstruiremos el surgimiento de la historia de la educación como un tema importante en la formación del profesorado de corte/orientación nacionalista y religiosa inspirada en Alemania y Francia. En la segunda sección se mostrará cómo este leitmotiv fue sustituido por una "revolución cognitiva" en la formación de los profesionales de la educación durante el período de la Guerra Fría que no sólo "sacrificó" la vaca sagrada de la historia de la educación en la formación docente, sino que también promovió el surgimiento de una ideología educativa ajena a la historia y fundamentalmente descontextualizada. La última sección describe cómo este cambio de motivación puede ser visto como una transición de mecanismos de control externos a internos en el control de los sistemas educativos. 


\section{La agenda nacional}

Los sistemas uniformes y profesionales de formación del profesorado no existieron sino hasta el siglo XIX. Como veremos, la formación docente fue un elemento importante de las estrategias aplicadas por los estados-nación europeos emergentes. Por un lado, la formación del profesorado se considera un medio de integración de la población; por otro lado, se le veía como una forma de hacer progresar a la nación y de fortalecer su posición competitiva en el campo internacional.

De esta manera, la estrategia de introducir un sistema escolar en todo el país estaba estrechamente ligada a la idea del Estado-nación que surgió de la Revolución Francesa, y, en Europa, desde el Congreso de Viena en particular (1814-1815). Por supuesto, no hubo discusiones sobre pedagogía en el Congreso de Viena. Sin embargo, el Congreso definió claramente estados delimitados territorialmente, cuya soberanía posteriormente tendría que ser consolidada. La mayoría de los nuevos estados - con la excepción de la ultraconservadora Prusia — promulgó constituciones que dieron fundamento legal a la nueva soberanía del Estado y transformaron a los habitantes en sujetos legales. Mientras que el ejército tenía la misión de defender la soberanía territorial externamente, a los nuevos sistemas escolares les correspondió integrar a la ciudadanía en el Estado de derecho. Esta tarea integradora requirió un medio de identificación — el ideal de la nación — que interpretara a la sociedad como una entidad unida no por el hecho de estar compuestos por individuos idénticos, sino que por las similitudes en la historia y, la mayoría de las veces, el lenguaje. En Luxemburgo, por ejemplo, las escuelas - junto con el ejército — se convirtieron en un elemento clave de la construcción de la nación en 1828. El "ideal identificativo" que iba a unir a los ciudadanos en el futuro - a pesar de las desigualdades de facto, sociales y económicas que los separaban — fue el de la unidad nacional: "Las escuelas primarias son la cuna de la ciudadanía. Por lo tanto, es necesario que nuestros jóvenes se eduquen en ellas para practicar todas las virtudes cívicas, morales y religiosas que deberían ser costumbre de un verdadero ciudadano" (citado en Witry, 1900, 34).

Las primeras leyes modernas sobre educación en Europa fueron promulgadas en el oeste y norte de Europa - en los Países Bajos y Dinamarca en 1814, Noruega en 1827, Suiza a comienzos de 1831, Francia en 1833, Bélgica y Suecia en 1842, y Luxemburgo en 1843. A finales del siglo XIX tales leyes ya se habían expandido por todo el continente. En general, las disposiciones legales para la formación de los docentes fueron promulgadas al mismo tiempo que las nuevas leyes educativas debido a que, en última instancia, los sistemas escolares creados recientemente necesitaban personal profesional debidamente calificado. Aunque los nuevos estados nacionales estaban preocupados principalmente por construir sus estructuras administrativas internas durante la primera mitad del siglo XIX, en la segunda mitad, también exhibían niveles crecientes de competitividad y hostilidad hacia otras naciones. La Guerra Franco-Prusiana (1870-1), que en última instancia provocó la unificación de los territorios del norte y del sur de Alemania con la fundación del Imperio Alemán en 1871, fue de particular importancia para la historia de la pedagogía en el ámbito de la formación del profesorado. Durante el período del canciller Otto von Bismarck, 
se adoptó la Constitución del Imperio Alemán el 16 de abril de 1871, abriendo el camino para la creación de un sistema escolar en todo el país, cuyo desarrollo fue financiado, nota bene, a través de las reparaciones de guerra provenientes de Francia.

\subsection{La "Historia de la Pedagogía" y la fundación del Imperio Alemán}

La unificación de la Confederación de Alemania del Norte con los grandes estados del sur, Württemberg y Baviera, bajo el dominio de Prusia para crear el Imperio Alemán fue, sobre todo, un tour de force cultural. De repente hubo una necesidad apremiante de obligar a territorios que antes habían sido enemigos para fundirse en una única nación. La fundación del Sindicato Aduanero Alemán en 1866 ya había puesto en marcha un proceso de unificación económica que precedió a la unificación política. Además, el "Discurso a la Nación Alemana" de Johann Gottlieb Fichte, presentado en Berlín en 1808 como una señal de oposición a la ocupación militar francesa, preparó el terreno ideológico. Fichte no solamente anunciaba que el alemán era el único idioma que permitía alcanzar un conocimiento verdadero, sino que una nación se definía esencialmente como una comunidad de personas que compartían la misma lengua materna (Craig, 1978; Fichte, 1808/2008). Los esfuerzos para lograr la unificación política, económica e ideológica exigieron la aceptación cultural; en última instancia, sólo así se podrían moldear distintos territorios para convertirlos en una comunidad imaginada (Anderson, 1983/2006). La difusión de los conocimientos necesarios para fomentar esta comunidad fue la misión que se asignó a las escuelas y en especial a los profesores, que tendrían que ser educados especialmente para esta noble tarea. En consecuencia, la educación del profesor no podía limitarse a los aspectos técnicos de la formación profesional (es decir, conocimientos especializados o metodologías de impartición). Por el contrario, tendría que incluir temas que el maestro en realidad no enseñaba en las escuelas primarias, tales como la psicología, los métodos didácticos y la historia de la pedagogía. De hecho, la enseñanza de la historia de la pedagogía había estado en boga desde hacía algún tiempo y, no por casualidad, se remonta a la ocupación francesa de Alemania después de 1805-1806, aunque sólo se convirtió en un tema de estudio diferenciado después de 1871. Fue en este tiempo que el género por primera vez adquirió toda su dimensión, y luego se extendió a otras naciones.

Este nuevo campo-es decir, la formación general de los docentes - requería sus propios materiales didácticos. Cuatro nuevos juegos de materiales didácticos para la formación de los docentes fueron publicados en Alemania durante el trienio 18711873, los cuales resultaron tener un gran éxito:

- 1871, de Friedrich Dittes: Geschichte der Erziehung und des Unterrichts: für dt. Volksschullehrer (Historia de la Educación e Instrucción: Para los alemanes maestros de escuelas públicas), que fue reimpreso en once ocasiones hasta 1903 y también apareció en francés en 1879, no sólo en Francia, sino de manera significativa, en Ginebra también;

- 1872, de Lorenz Kellner: Kurze und Geschichte der Erziehung des Unterrichtes mit verwaltender Rücksicht auf das Volksschulwesen (Breve Historia de la Educación y 
de la Enseñanza, considerando el aspecto Administrativo del Sistema Público de Educación), que fue reimpreso once veces hasta 1899;

- 1873, de Joseph Kehrein: Überblick der Geschichte der Erziehung und des Unterrichts: für Zöglinge der und zur Lehrerseminare Vorbereitung auf die Allg. Bestimmungen angeordneten Prüfungen (Resumen de la Historia de la Educación e Instrucción: Para estudiantes de escuelas normales y para la Preparación para Exámenes Generales), que fue reeditado dieciséis veces hasta 1922;

- también en 1873, el best-seller absoluto entre todos los textos de historia, Geschichte der Pädagogik, en Vorbildern und Bildern (Historia de la Pedagogía en ejemplos y fotografías) de August Schorn, cuya 32a edición ocurrió en 1922.

Todas estas "historias de la educación" tienen una marcada tendencia nacionalista, algo que queda claramente demostrado en la selección de pedagogos incluidos en las obras. ${ }^{2}$ Como se ve en el siguiente gráfico, los alemanes principalmente se referían a las grandes figuras de la educación alemana:

\section{Autores citados en los textos alemanes de Historia de la educación, 1871-1873}

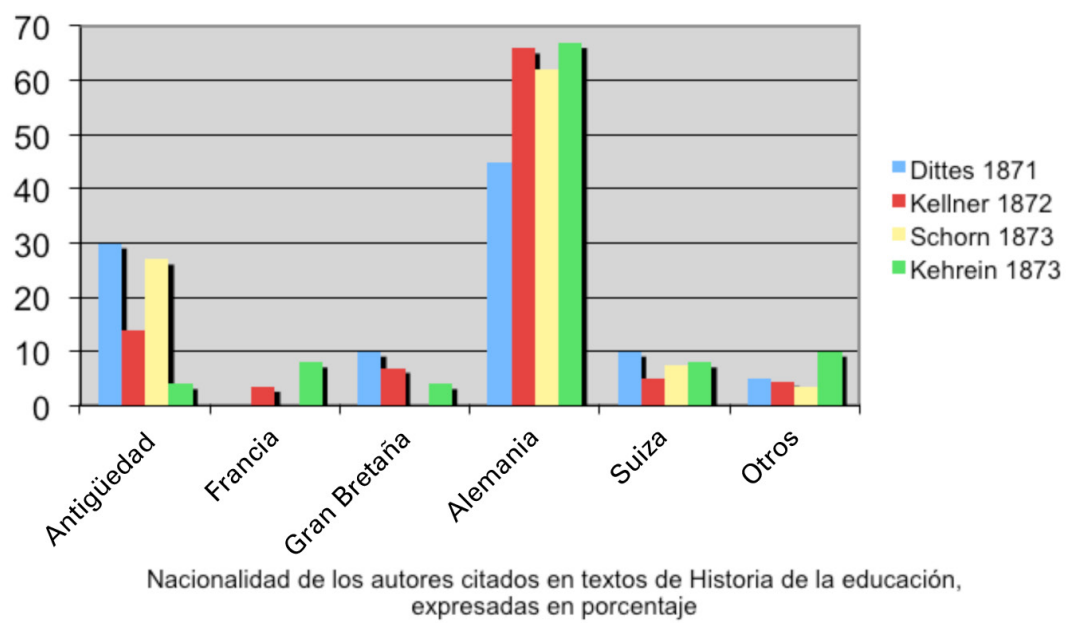

A excepción de Dittes (que escribió su libro previo a la fundación del Imperio Alemán), dos tercios de las citas indicadas por los otros tres autores son de educadores alemanes y las fuentes de la antigüedad aparecen de manera más prominente que en autores de Francia o Inglaterra. Gracias a Rousseau y Pestalozzi, Suiza aparece por sobre las otras dos grandes potencias europeas. 


\subsection{Imitando a los alemanes: Historias francesas de la educación}

Tras la derrota de Francia a manos de Prusia entre 1870 y 1871, podemos reconocer esfuerzos similares para instituir un sistema de educación a nivel nacional en Francia. El vecino occidental de Alemania procedió a desarrollar su propio sistema educativo nacional, centrado específicamente en la formación del profesorado, aunque esto ocurrió unos diez años después que en Alemania. Las cátedras en educación dedicadas exclusivamente a la formación docente no se establecieron hasta la década de 1880 . En Francia, como en Alemania, los materiales de enseñanza eran necesarios y los textos elaborados buscaban fortalecer el carácter nacionalista y moral de los futuros profesores. La Ley de 1882 estableció una base legal para el nuevo sistema de formación de profesores en Francia, y en los años siguientes se publicó diversas historias de la educación y/o instrucción. La primera de ellas resultó la más exitosa: Histoire de la Pédagogie (Historia de la Pedagogía) de Gabriel Compayré, que abarcó el período comprendido desde la antigüedad hasta el presente y se publicó en 1883 . Su $28^{a}$ edición se publicó de 1917 y también hay una referencia a una 33a edición sin fecha. En las historias francesas de la educación nos encontramos con una situación muy similar en cuanto a la selección de los educadores que fueron citados. Los escritores franceses primordialmente citaron a educadores franceses, lo que demuestra que su orientación no tuvo una perspectiva menos nacionalista que la de sus vecinos alemanes.

\section{Autores citados en textos franceses de Historia de la educación, 1871-1891}

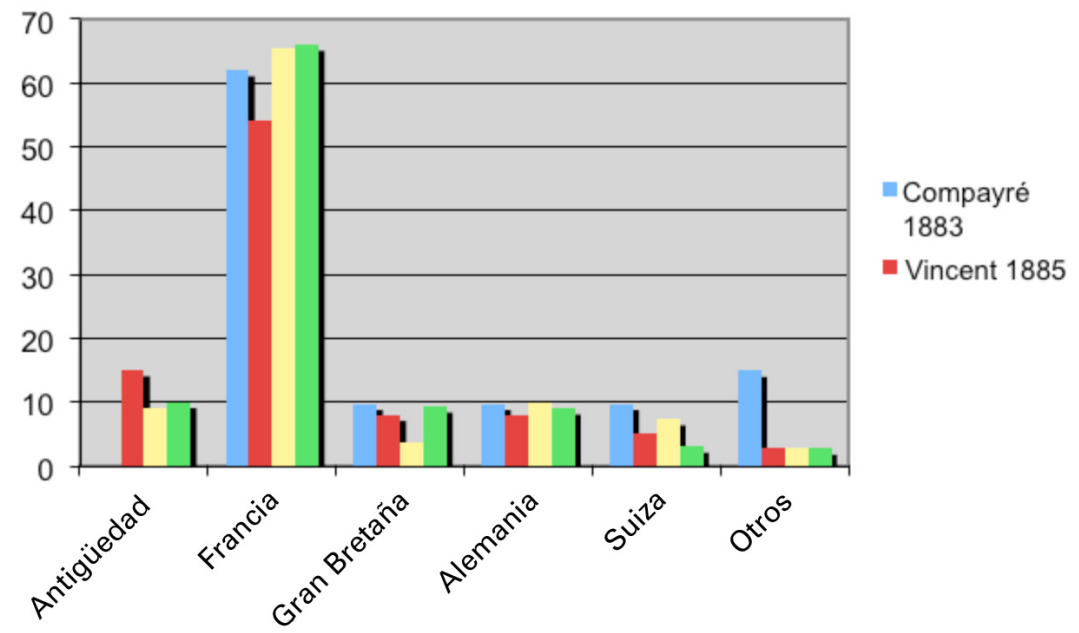

Nacionalidad de los autores citados, expresada en porcentaje 
Como se observa en las cifras, los escritores franceses representaron entre un 60 y un $66 \%$ de los autores citados; autores de la antigüedad o de otras nacionalidades representaron porcentajes equitativos de alrededor de un $10 \%$. Si combinamos los cuatro textos de Historia alemanes y los cuatro franceses, podremos apreciar el énfasis que se asignaba de manera paralela a los paradigmas nacionales en la siguiente figura:

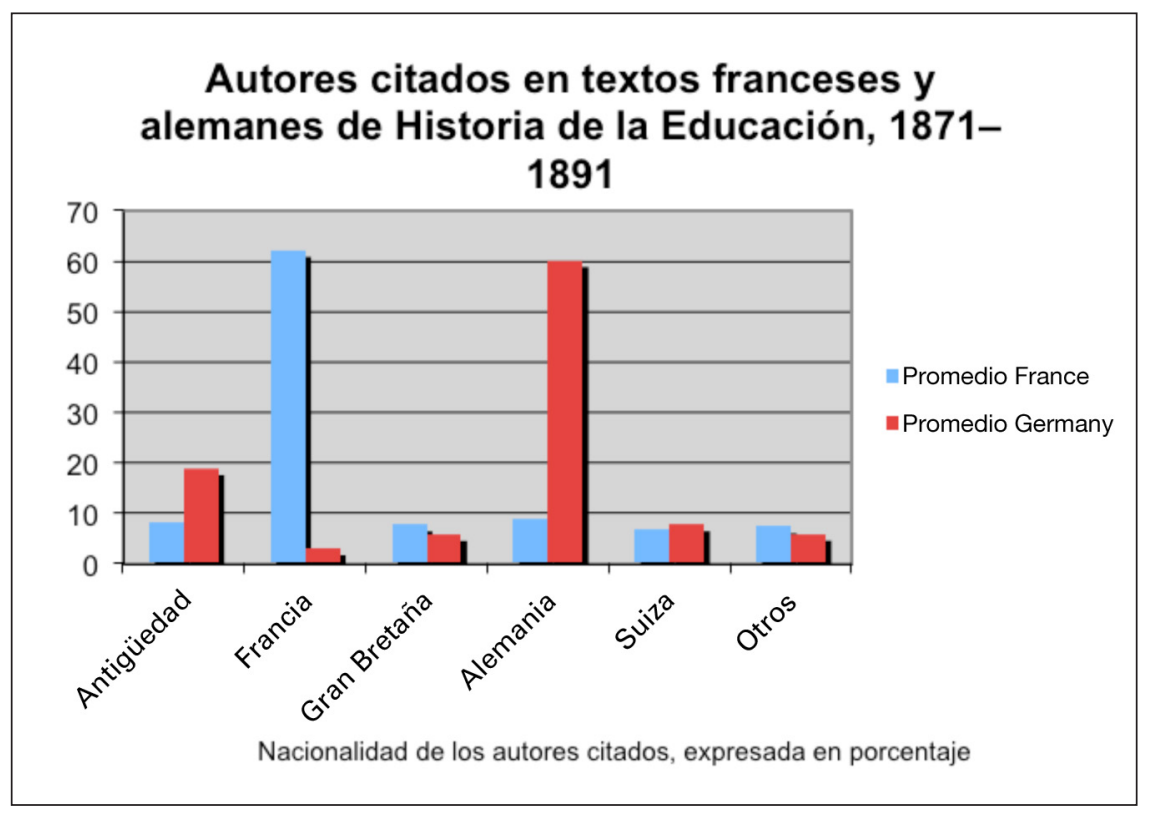

Todos estos autores coincidieron en que la formación del profesorado no debe ser puramente académica, sino que debe tener un beneficio práctico. Así, como Compayré lo expuso, hay que estudiar la historia de la educación no sólo con un "espíritu de erudición", sino que, por razones prácticas "a fin de buscar verdades duraderas" (XIV). Sin embargo, el beneficio intelectual no fue suficiente para Compayré: "¿De verdad creen que para dar aliento a los esfuerzos de nuestros maestros no es de ninguna utilidad presentarles esos maravillosos modelos de virtud pedagógica llamados Comenius, Rolin o Pestalozzi? Al asumir su pesada carga día tras día, no se sentiría el profesor reconfortado y apoyado, ¿̇no se sentiría en mejores condiciones de abordar su posición al frente de la clase, donde tan grandes dificultades y tribulaciones le esperan...? "(XV). De manera similar, Dittes también trató de obtener un beneficio moral y práctico de la historia de la educación: "La peregrinación por este reino llenará al maestro de amor y pasión por un llamado que es ennoblecido y santificado por sus luminarias gloriosas, con esas ideas en las que todos los intentos de mejorar la humanidad deben encontrar sus verdaderos objetivos, a través de estos grandes paradigmas de perseverancia y abnegación al servicio de la civilización "(9f).

Sin embargo, la "civilización" fue concebida a lo largo de líneas nacionales, como lo demuestra la selección de fuentes. "El amor y la pasión" por su profesión que debía 
estar inculcado en el maestro debía ser evocado por los héroes nacionales - y no los internacionales, con las excepciones ocasionales de Rousseau en Francia y Pestalozzi en Alemania. Por otra parte, siempre se pensó que el amor que debía ser estimulado por estas grandes figuras históricas debía operar de forma prospectiva: la historia de la educación tuvo un pasado distinto que daría lugar a una meta situada en el presente y en el futuro inmediato. Así, en ambos países, los textos históricos son ordenados cronológicamente según las épocas. Compayré diferencia entre la antigüedad clásica, la Edad Media, el Renacimiento y la Modernidad, mientras que Dittes marca una distinción entre los "pueblos antiguos" y los "alemanes." Él divide los "alemanes" en cinco categorías, las dos primeras pre-Lutero y las tres últimas post-Lutero. Compayré representa las épocas personificadas por las "grandes figuras" (XIII), o, como lo expresó Dittes, “innovadores líderes de la raza humana”, a quienes el autor atribuía principalmente un origen antiguo o alemán (9). Con estos antecedentes, se puede observar que estos autores no creían estar escribiendo historias de la educación, sino más bien, la historia de la educación, lo que en definitiva fue equivalente a documentar el progreso cultural, sólo que en un caso el progreso tuvo su epicentro en Alemania y, en el otro, en Francia. ${ }^{3}$

\subsection{El ideal de una nación basada en la religión}

La idea de la nación no era un proyecto racionalista, sino uno idealista y emocional. Como resultado, existía la creencia de que la instrucción de los estudiantes en varias materias no sería suficiente por sí sola para unificar a la población y conseguir su apoyo al Estado-nación. Más bien, era necesario que los futuros docentes sintieran "amor y pasión" por su quehacer patriótico y que estuviesen imbuidos con un celo ideológico por su misión. En consecuencia, los programas escolares a nivel nacional eran sesgados, y este no fue sólo el caso de asignaturas como la historia o la geografía. El objetivo de estas diversas historias de la educación era nada menos que inspirar una identificación casi religiosa con la nación por parte del profesor.

Este aspecto "misional" es evidente en las historias seleccionadas cuando uno considera las formas en que los autores describen el alcance histórico de los progresos que se atribuyen, en parte, a la educación. Compayré consideraba que su obra de historia era "muestra del progreso de la pedagogía, ya que poco a poco se eleva del instinto a la reflexión, de la naturaleza al arte." La pedagogía es capaz de "revelar este hermoso espectáculo que nos da la humanidad, que crece sin fin" (XIII). Las lecciones definitivas sobre el progreso histórico debían ser obtenidas mediante una "ciencia de la educación", que aún no se había creado. Los pasajes finales de su Histoire de la Pédagogie (Historia de la Pedagogía) muestran cómo Compayré imaginaba el progreso histórico. A la vez que rechazaba una comprensión de la evolución que preveía la aparición de una raza de superhombres, este autor creía en el poder de una educación adecuada. Según Compayré, el progreso de la humanidad surgió de la reflexión razonada sobre lo que constituye una educación adecuada, y esta reflexión tenía que ser más amplia, más extendida, con más diligencia, y más liberal que nunca. Por lo tanto, Compayré pensó que tenía sentido basar esta nueva forma de educación en 
la psicología empírica, con el fin de crear una science de l'éducation respaldada por ejemplos históricos, lo que podría formular una teoría de la educación: "Se requiere la creación de una psicología del niño y que esta esté bien formulada y, una vez que tal psicología haya sido creada, que se permita la reflexión para determinar todas las consecuencias que ello implique "(484). Esta forma de cientificismo racionalista no era universal, sino que reflejaba la ideología racionalista a la que Francia se había comprometido desde la Revolución Francesa. La racionalidad en este sentido no fue concebida desde un sentido universal, sino que francés. Así lo demuestra el pasaje final del libro de Issaurat: "Ahora, la filosofía de la enseñanza que debe prevalecer en la educación nacional, en las instituciones del Estado, la única filosofía que responde a las necesidades de nuestra época, parafraseando la forma en que un académico lo expresó, para cumplir con esas demandas que cada día requieren satisfacer más y más necesidades, es el espíritu de la ciencia en el sentido más amplio ... el de una ciencia absolutamente secular y materialista" (Issaurat, 1886, 493f.).

Uno puede diferenciar una base comparable que se puede identificar más claramente como religiosa en los escritos históricos alemanes. Dittes resumió sus ideas, que registró justo antes de la conclusión de la guerra entre Francia y Alemania, de la siguiente manera: "Casi todos los requisitos esenciales de la pedagogía no han sido reconocidos legalmente por el momento y tantas reformas que consideramos esenciales siguen existiendo sólo en el papel. Pero si comparamos el presente con el pasado, podemos regocijarnos con todo nuestro corazón acerca de los progresos que se han hecho... la ciencia pedagógica y el arte aún no han progresado tanto como para que podamos estar conformes, pero sí lo suficiente como para que puedan cumplir su misión" (Dittes, 1871, 216). El vocabulario de la salvación cristiana, tal y como aparece aquí en el concepto de "misión", es apenas una coincidencia. De acuerdo con este espíritu, la historia de Kellner también concluye con la invocación: "El que no despierte, eleve, e intensifique la sensibilidad religiosa en su programa educativo, quién no lo ubique deliberadamente a la vanguardia, con plena conciencia de los conflictos existentes, tal persona, sin importar cuán favorables o humanitarias sean las circunstancias, nunca logrará lo que es verdaderamente fructífero, agradable a Dios, o duradero. ¡Esta es y seguirá siendo la lección de la historia de la educación!"(Kellner, 1872, 261). En el mismo sentido, el libro de Schorn termina con estas palabras: "En los nuevos caminos, ahora probados, esperamos que las escuelas de la patria, cuyas responsabilidades están en constante aumento, permanezcan en la bendición de Dios" (Schorn, 1873, 361).

\section{La agenda internacional}

La filosofía de la educación nacionalista y basada en la historia, que dominaba la formación del profesorado se sometió a un proceso de cambio después de la Primera Guerra Mundial, el que se aceleró a partir de 1945; la tradición dio paso a una visión esencialmente ajena a la historia de un "globo educativo armónico" (Tröhler, 2010). Esta nueva ideología educativa en última instancia fomentó la descontextualización cultural de la política de la educación en general y de la política de formación del 
profesorado en particular, en un proceso que continúa hasta nuestros días. En el "mundo nuevo" que se crearía, ya no se esperaría que los maestros llevaran a cabo su trabajo de una manera moral o emocional, sino que fueran racionales, lógicos y alejados de las moralejas. Los encargados de formular las políticas educativas esperaban que al priorizar los aspectos científico, cognitivo y tecnológico de la educación, sería posible crear un mundo libre de agresivos Estados-nación y dar forma a un mundo de paz sin un pasado o particularidades y limitaciones locales. En lugar de ello, los problemas en este mundo futuro deben resolverse de forma pragmática, con la ayuda de métodos científicos y del conocimiento científico (Bell 1960). Un rasgo paradójico que muy pocas veces ha sido objeto de una exploración profunda es que esta narrativa, a pesar de toda su retórica de tendencia hacia lo científico, no obstante, ha seguido muy cercana a lo religioso, aunque no en relación con la nación o la patria.

¿Cómo podemos explicar estas transformaciones complejas en un período de tiempo relativamente corto? Tres avances estrechamente relacionados fueron los principales responsables: el surgimiento de un nuevo paradigma internacional de tendencia hacia lo científico a partir del período de entreguerras; la marcha triunfal de la psicología y su "revolución cognitiva" en la investigación y en la formulación de políticas en el ámbito de la educación (a partir de la década de 1950 en los Estados Unidos); y el ascenso de una nueva visión acerca de la naturaleza humana, una que buscaba la mejora tecnológica y sistemática de la humanidad basada en las ideas de la cibernética y la inteligencia artificial.

\subsection{Tendencias hacia la academización de la educación docente en el período entre guerras}

A partir de la Primera Guerra Mundial podemos observar tendencias marcadas hacia la internacionalización y la búsqueda científica en casi todas las sociedades occidentales modernas, estas tendencias fueron el fundamento básico de un programa transnacional de ingeniería social. La investigación histórica revela un claro esfuerzo por promover la cooperación interdisciplinaria e internacional entre las diferentes disciplinas científicas con el fin de fomentar nuevos sistemas para garantizar la integridad de las sociedades que estaban siendo sometidas a las fuerzas centrífugas de la modernidad. La principal fuerza impulsora detrás de estos planes fue un grupo transnacional y de élite de expertos científicamente calificados. Los ámbitos de actividad en los que se interesaban abordaron casi todos los aspectos de la sociedad. A través de diversos sectores de la vida social, como la atención de salud, la vigilancia y la educación, las ideas discutidas a nivel internacional para la normalización, racionalización y orientación hacia lo científico, pronto dieron lugar a la creación de paradigmas que llevaron a los esfuerzos de reforma en muchos países. En última instancia estas propuestas dieron lugar a las técnicas de planificación social que todavía se aplican hoy en día y que también demostraron ser útiles para las dictaduras totalitarias (Dickinson, 2004; Etzemüller, 2009, 2010). En el ámbito de la educación, estas ideas van desde el "multilateralismo educativo” (Fuchs, 2006, 167) adoptado por la Liga de las Naciones en 1919, hasta los esfuerzos en políticas educacionales científicas de la alianza fascista que estuvo activa a nivel internacional (Bernhard y Rohstock, de próxima publicación). 
Las tendencias hacia la internacionalización y la búsqueda científica tuvieron un impacto significativo en la formación del profesorado. Impulsados por el progreso científico en la psicología y la elevación correspondiente de la pedagogía como ciencia sobre la que se enseña e investiga en el ámbito universitario (para Francia, Alemania y Suiza, ver Condette, 2007; Drewek, 2002; Hofstetter, 2009), cada vez más y más políticos de los Estados Unidos y Europa hicieron campañas a favor de la profesionalización en la formación del profesorado y de una reformulación de su objeto de estudio (Nelles, 1995). Los esfuerzos hacia lo científico se reflejaron inicialmente en los intentos de muchas naciones occidentales para facilitar una formación docente más académica. La Constitución de Weimar de 1919, por ejemplo, contenía disposiciones para la reformulación a nivel nacional de la formación docente en Alemania, la que debía estar orientada hacia "los principios que se aplican en general a la educación superior" (Constitución de Weimar, artículo 143). Esto allanó el camino para que la formación del profesorado se integrara a la universidad. En Inglaterra y en los EE.UU. se puede apreciar intentos similares para facilitar una formación docente más académica; en este último país se produjo una oleada de reestructuración en la que las escuelas normales de antes se transformaron en escuelas para docentes o en universidades estatales (Labaree, 2008, 295; Tyack, 1967). Estos esfuerzos fueron inspirados por la exitosa experiencia previa del establecimiento de escuelas especializadas para estudios de posgrado en las disciplinas de la medicina y el derecho. Con sus cánones universales de conocimiento, su proximidad a la investigación, y sus pruebas estandarizadas, estas instituciones representaban los modelos ideales para la profesionalización exitosa de una ocupación (Ravitch, 2002).

Por lo tanto, en cierta medida, la academización de la formación docente se convirtió en un fenómeno que se extendió por varias naciones y su orientación hacia temas internacionales se reflejó también en el plano organizativo y sustantivo. En la primera mitad del siglo XX, se fundaron las asociaciones internacionales de maestros que operaban a escala mundial, como la Organización Mundial de Asociaciones de Profesores de Escuelas Públicas en 1926 y la Organización Mundial de Profesores de Educación Superior, que ya existía antes de la Primera Guerra Mundial (Fuchs, 2006). Al mismo tiempo, los académicos y los políticos con orientación internacional colocaron la "mente internacional" (Butler, 1912) en el centro de sus esfuerzos orientados a la transnacionalización de la formación docente. La "mente internacional" se definió como "el hábito fijo de pensamiento y acción que ve a las varias naciones del mundo civilizado como iguales que cooperan en la promoción del progreso de la civilización, el desarrollo del comercio y la industria, además de la difusión de las ciencias y la educación a lo largo del mundo" (Butler, citado por Kuehl \& Dunn, 1997, 65). Finalmente, tales sentimientos resultaron ser más que una quimera. Por ejemplo, una encuesta llevada a cabo por la Liga de las Naciones en 1929 reveló el sorprendente hallazgo de que casi todas las escuelas de formación docente de los EE.UU. "están preparando a sus estudiantes para formar a sus futuros alumnos según los lineamientos de la amistad mundial" (World Federation of Education Associations, 1929, 76).

En la mayoría de los casos, sin embargo, los esfuerzos para internacionalizar y dar un perfil académico a la formación del profesorado en los años 1920 y 1930 se 
limitaron al plano puramente discursivo (Sandfuchs, 1978, Müller-Rolli, 1989, 241; Bölling, 1978). Por ejemplo, en Inglaterra y Alemania, hubo una gran resistencia a la integración de la formación docente en la universidad (Thomas, 1990; Schellack y Große, 2007). Eduard Spranger, por ejemplo, figura alemana prominente de la "geisteswissenschaftliche Pädagogik" (pedagogía humanista), se volvió en contra de los esfuerzos de dar un aspecto más científico a la pedagogía, no sólo porque afectaban a la idea alemana tradicional de la universidad, sino también para evitar poner en peligro los puestos de poder que la pedagogía acababa de adquirir en la universidad en el curso de su academización (Becker, 1980, 249). En muchos países, sobre todo en los EE.UU., Alemania y Francia, el proceso de plena incorporación formal de la formación docente en la universidad tendría que esperar algún tiempo. En este sentido los es fuerzos se desarrollaron a ritmos variados en los distintos países, pero se intensificaron notablemente en las décadas de 1960 y 1970 y, a la larga, las reformas se llevaron a cabo en todos los países occidentales durante la primera década del siglo XXI. Mientras que los EE.UU., Finlandia y Alemania habían impulsado la incorporación de instituciones de formación de docentes en sus sistemas universitarios ya en la década de 1960, y en las décadas de 1970 y 1980 se habían completado en lo fundamental estos esfuerzos (para los EE.UU., ver Labaree, 2008; para Finlandia, consulte Simola, 1992, 1998; en Alemania, ver Führ, 1989), Dinamarca, Francia y Austria no integraron completamente la formación docente sino hasta hace muy poco (Hopmann, 2008, 7). La intención era, como Hannu Simola describió para Finlandia, "transformar la enseñanza 'de una actividad casual a una racional"" (Simola, 1998, 343).

\subsection{Internacionalización y cientifización de la educación de docentes desde 1945}

La comprensión social de la ciencia se transformó en el transcurso de la Segunda Guerra Mundial, y esto aceleró el proceso de academización. Según varios estudios históricos han demostrado convincentemente, durante la década de 1940 hubo una creciente percepción de que la ciencia tiene el potencial de resolver todos los problemas, una convicción que surgió por primera vez en los Estados Unidos, pero se extendió progresivamente a Europa (ver Rohstock, 2012). Esta creencia era notoria sobre todo en el ámbito de la política. Los contemporáneos estaban de acuerdo en general en que la victoria aliada había sido posible gracias a los avances tecnológicos de la investigación militar, como la que se llevó a cabo en el MIT (Stewart, 1980; Leslie, 1993). A la luz de las crecientes tensiones con la Unión Soviética, la ciencia fue nuevamente llamada a las armas por los políticos; la investigación y la tecnología eran vistas como las claves para prevalecer en esta nueva carrera competitiva (McDougall, 1985).

La experiencia de la $2^{\text {a }}$ Guerra Mundial también consolidó entre los propios investigadores la creencia en la capacidad universal de la ciencia para resolver todos los problemas. Casi ningún científico en el ámbito público expresó la menor duda de que la racionalidad y la inteligencia humana podrían trazar el camino hacia un mundo mejor, ya sea a través del progreso tecnológico o mediante la evolución de la humanidad misma. La utopía científica de B.F. Skinner, descrita en Walden II en 1948, preveía la creación de una comunidad feliz de científicos perfeccionada a través de 
la ingeniería cultural y las tecnologías de auto-control (Skinner, 1948). Al final, esta visión no estaba tan lejos de las predicciones de muchos de sus colegas acerca del funcionamiento futuro del mundo. Jerrold Zacharias, por ejemplo, un físico del servicio militar y miembro de la élite científica estadounidense durante la Época de posguerra, habló en nombre de sus colegas cuando expresó su convicción inalterable de que casi todos los problemas que enfrentaba la sociedad estadounidense podrían ser resueltos a través del "intelecto de primera clase" (Zacarías citado por Rudolph, 2002, 90).

De acuerdo a muchos en la elite intelectual de EE.UU., una "crisis de la educación" había estado aquejando al país desde el fin de la 2a Guerra Mundial. Numerosos críticos asignaban la responsabilidad de la situación del sistema educativo al compromiso con la educación progresista que había dominado la filosofía de la educación en los EE.UU. desde la década de 1920, así como a su largo brazo pedagógico que buscó en las escuelas, el movimiento de educación ajustada a la vida. En total concordancia con el nuevo paradigma de cientifización, Jerome Bruner, psicólogo líder de la época, indicaba que la educación progresiva se caracterizaba por una "discontinuidad de las fronteras del conocimiento" y una "falta de interés en la estructura intelectual de las actividades de clase" (Bruner citado por Olson, 2007, 33). Por lo tanto, no fueron los educadores sino los científicos, especialmente de las disciplinas que habían sido cruciales para el esfuerzo de guerra - es decir, la psicología, las matemáticas, la química, la física y la biología - quienes finalmente jugaron un papel dominante en los debates sobre el futuro diseño de los planes de estudios, los nuevos sistemas de formación del profesorado y la reforma de las universidades. Su principal objetivo, como ha sido demostrado por estudios recientemente publicados sobre la historia de la educación y la ciencia, fue la cientifización y la intelectualización de la enseñanza en el aula (Hartman, 2008, Rudolph, 2002; Rohstock, en prensa 2012).

La psicología cognitiva, que surgió después de la 2a Guerra Mundial, figuró de manera significativa en este proceso. El llamado "giro cognitivo", que ha sido poco estudiado por los historiadores de la ciencia y casi exclusivamente elaborado por sus protagonistas (Bruner, 1983; Miller, 2003), estableció una visión del sistema educativo en general y de la formación del profesorado en particular, que sigue siendo dominante en la actualidad. Con su promesa de un alejarse totalmente del modelo conductista que dominaba previamente en la enseñanza y el aprendizaje, su enfoque en la investigación sobre la actividad mental como una forma de tratamiento de la información inspirada por la cibernética y su orientación hacia las premisas derivadas de las ciencias naturales en cuanto a la producción del conocimiento (incluido el requisito de que las hipótesis sean desarrolladas y comprobadas experimentalmente, así como la fe en la posibilidad de objetivizar y cuantificar todo el conocimiento), la psicología cognitiva contenía precisamente la dosis exacta de revolución y de renovación inspirada en la ciencia como para catalizar su rápida asimilación en el mundo de la investigación, así como en el ámbito político. Inspirado por el "giro cognitivo", el filósofo de la ciencia norteamericano Thomas Kuhn escribió una tesis sobre la naturaleza de las revoluciones científicas, que pronto alcanzó notoriedad en todo el mundo; el eslogan del "cambio de paradigma" científico que se originó con Kuhn 
sigue siendo omnipresente en la actualidad (Kuhn 1962). Los políticos estadounidenses también estaban hipnotizados por la promesa de una renovación científica en el campo de la educación. Cuando dos de los protagonistas principales del giro cognitivo en EE.UU., los psicólogos y antiguos expertos militares Jerome Seymour Bruner y George Armitage Miller, se acercaron a John Gardener, entonces presidente de la Corporación Carnegie de Nueva York, para instarle a proporcionar financiamiento inicial para un Centro de Estudios Cognitivos, su respuesta inmediata fue la oferta de 250.000 dólares. Poco después, la Fundación Ford se enteró del proyecto; no sólo invirtió 250.000 dólares también, sino que pronto cerró su programa para las ciencias de la conducta, lo que cerró la posibilidad de financiamiento a toda una generación de investigadores conductistas (Bruner, 1983, 122, 124). El apoyo de los representantes de la élite política, desde Sargent Shriver a John F. Kennedy y Lyndon B. Johnson, mostró que la elite estadounidense se había convencido rápidamente acerca de las posibilidades que ofrecía la psicología cognitiva para la reforma del sistema educativo. Los partidarios de la psicología cognitiva aprovecharon las nuevas oportunidades que surgieron en el campo de la educación: el hecho de que el gobierno federal en los EE.UU. empezara a intervenir en lo que la Constitución de los EE.UU. garantizaba como un sistema de escuelas de administración local — algo que incluso Sargent Shriver tuvo que admitir que significaba "dinamita política” — se debió en gran parte a personajes como Jerome S. Bruner y George A. Miller (Shriver, citado por Bruner, 1980, 136). Ellos hábilmente aprovecharon sus contactos en la Casa Blanca y así pudieron mantener su influencia a largo plazo. En cualquier caso, hubo una verdadera oleada de nuevas iniciativas que emanaban del centro cognitivo que Bruner y Miller habían creado a principios de la década de 1960. En los años siguientes, instituciones similares se extendieron, y el apellido "cognitivo" se convirtió en una marca de calidad con alto valor de reconocimiento (Boden, 2006).

En el ámbito de las escuelas, los defensores estadounidenses de la psicología cognitiva en un primer momento no se centraron tanto en la formación de los profesores sino que más bien orientaron todos sus esfuerzos a la manera de educar a los estudiantes. Su objetivo principal era reformar el plan de estudios. En la célebre Conferencia de Woods Hole, que duró 10 días, en 1958, especialistas en la materia, junto con psicólogos, desarrollaron nuevos planes de enseñanza y libros de texto que tenían como objetivo nada menos que la reformulación completa del plan de estudios. A partir de ahora, la capacidad para resolver problemas abstractos estaría a la vanguardia del aprendizaje en cada disciplina individual, y las operaciones lógicas junto con la comprensión general de un tema tendrían preferencia sobre su dominio total; en el futuro, al igual que había ocurrido con la investigación científica después de la Segunda Guerra Mundial, la enseñanza estaría orientada a metas obligatorias propuestas. Estructura fue la nueva palabra mágica. Las escuelas tendrían que subordinarse a este principio y el profesor estaría a cargo de proporcionar al estudiante las estructuras del conocimiento. Jerome Bruner llama a este proceso "andamiaje"; Bruner explícitamente quería transferir este modelo de ingeniería a la práctica pedagógica. Él creía que las futuras escuelas permitirían al estudiante resolver problemas desconocidos en contextos totalmente diferentes de los que ya había enfrentado (Bruner, 1960; Olson, 
2007). De acuerdo con esta perspectiva, la función de la escuela era transformar la mente humana en un sistema de decodificación que podría descifrar todos los códigos imaginables que pudieran surgir en un entorno futuro (Brunner 2006). De esta manera, las formas de pensar en la aplicación general y dirigida al futuro encontraron su lugar en las salas de clases estadounidenses y, desde esa posición, suprimieron la estructura tradicional del objeto de estudio orientado al presente, contextualizado espacial, histórica y culturalmente.

El hecho de que este tipo de reforma corría de manera completamente opuesta a la finalidad de la racionalización en el contexto de la Guerra Fría nunca fue más evidente que en Woods Hole. Como Jerome Bruner y sus colegas académicos subrayaron en repetidas ocasiones durante su reunión en Cape Cod, las escuelas en el futuro tendrían que funcionar de manera análoga a las armas y a los sistemas de defensa desarrollados para la disuasión durante la Guerra Fría. Un estudio que circuló entre los participantes de la conferencia hizo hincapié en que "los objetivos de la educación (...), expresados en términos de las funciones humanas y las tareas a realizar (...) pueden ser especificados de manera tan exacta y objetiva como las funciones humanas y las tareas presentes en el Sistema de Armas Atlas "(Bruner, citado por Rudolph, 2002, 99).

En el camino hacia la aplicación de este programa, el maestro era considerado básicamente como "un obstáculo." Como las acciones de la élite científica en última instancia demostrarían, durante la cientifización de las aulas también se lleva a cabo la "despedagogización" de la instrucción. Desde el principio, estos investigadores tenían grandes dudas sobre si el profesor "ordinario" llegaría a cumplir con las exigencias intelectuales del nuevo sistema de enseñanza o si sería capaz de impartir las nuevas formas elaboradas para el aprendizaje. De hecho, los profesores no habían sido educados hasta ese momento - según muchos científicos observaron con desdén — en "la ciencia de vanguardia", sino que sus estudios se habían centrado sobre todo en la educación (Rudolph, 2002, 66). La tecnologización de la enseñanza en el aula prometió una solución a este dilema. El uso de máquinas para la enseñanza y el aprendizaje y de películas educativas podría minimizar el impacto del profesorado antiguo como también podrían hacerlo las guías de trabajo compiladas en gruesos volúmenes que los educadores debían presentar aprensivamente durante el período de clase (Rohstock, 2012). Estas medidas tenían por objeto limitar el papel del profesor a un "gestor efectivo de instrucción." La incorporación del docente en "un diseño sistemático de la instrucción debería reducir el número de situaciones de enseñanza-aprendizaje ineficientes, ineficaces y no esenciales" (Razik, 1972, 60). No era la formación del profesor, sino que su educación continua el tema central. Los profesores serían entrenados para su nueva misión de enseñanza mediante el acompañamiento (OECD, 1977, 57) por medio de cursos de capacitación de verano, seminarios y talleres. Casi nadie estaba pensando en una reforma integral de la formación del profesorado en este sentido antes de la década de 1970.

\subsection{La "revolución cognitiva" en la preparación de docentes desde la década de 1980}

El hecho de que el retroceso presupuestado en el papel de los educadores en la enseñanza de aula no sólo resultara ser ingenuo sino también fuera insuficiente para 
lo que se requería se convirtió en el foco de críticas crecientes durante la segunda mitad de la década de 1970. La pregunta recurrente que se planteó fue cómo los estudiantes podrían participar en el aprendizaje exploratorio "cuando el maestro debía ser considerado como un mero técnico" (Tanner y Tanner, 1987, 189). Además, la investigación pedagógica había descubierto que los profesores normalmente no utilizaban los materiales didácticos que habían sido desarrolladas por la élite científica de la forma prevista. En lugar de aplicar los métodos destinados a promover las capacidades cognitivas abstractas, continuaron bombardeando a los estudiantes con hechos (Goodlad, 1966, Cohen, 1973, 33). Por esta razón, las autoridades educativas pronto dejaron de buscar conseguir un aumento gradual en la innovación o mejoras a través de la capacitación paralelamente al trabajo, sino que buscaron "cambios radicales" en la formación docente como parte de una reforma general del sistema educativo (Yates, 1970). La OCDE incluso vio que el progreso del mundo occidental dependía de la reforma sistemática de la educación docente, afirmando que "hay pocas esperanzas de progreso sin programas de formación continua sistemática. Así, la educación de los docentes estará en el centro de cualquier programa de reforma de la educación" (OCDE, 1974a, 9). De hecho, desde la década de 1970, la OCDE ha dedicado una mayor atención a la reforma de la formación docente (OCDE, 1976, 1974b, 1971a, 1971b).

En el marco de estos esfuerzos reformistas un objetivo era rediseñar los currículos de formación docente. A pesar de toda la retórica sobre cientifización, el grado en el que este esfuerzo fue impulsado por la Guerra Fría y por el objetivo de desnacionalizar al mundo occidental se vuelve evidente cuando se echa un vistazo a las instituciones encargadas de reformular la formación del profesorado y a los programas que propusieron. El esfuerzo para moldear los sistemas educativos a la imagen de los sistemas de defensa que ya se había observado en la reforma del plan de estudios de EE.UU., se extendió ahora a nivel internacional. La Organización del Tratado del Atlántico Norte (OTAN), una organización que no tenía un rol en el área de la política educativa y que era el epítome de una alianza de defensa, promovió un programa internacional de largo alcance para la reforma de la formación docente. La OTAN fue aún más lejos y construyó el Centro de Información para Maestros del Atlántico (AICT, por su acrónimo en inglés) en Londres, que trató de ejercer una influencia directa sobre los educadores en las aulas europeas mediante toda una serie de seminarios, a partir de fines de la década de 1960. Las órdenes de marcha eran absolutamente claras: en estos cursos de gran concurrencia, con títulos como "Los estereotipos nacionales: un reto educativo" (1968); "La enseñanza sobre el impacto norteamericano en Europa" (1969); "La enseñanza sobre la seguridad colectiva y el conflicto" (1971); y "La televisión y la enseñanza acerca de los asuntos internacionales en las escuelas" (1972); el objetivo primario y crucial era lograr la solidaridad entre Estados Unidos y Europa, además de la unidad estratégica de Occidente en una comunidad de defensa que abarcaba toda la sociedad. Los maestros y las escuelas se alistaron para lograr este objetivo. El modo de pensar de las conferencias financiadas por la OTAN fue que el personal docente europeo tenía la misión de educar a los jóvenes acerca de la "dependencia total" de Europa de los Estados Unidos de tal manera 
que se "aprendiera a valorar" la participación de los norteamericanos. El mandato asignado a los educadores exigía guiar a los estudiantes a comprender que el papel dominante de los EE.UU. como líder mundial cumplía con los mejores intereses de todos los europeos (AICT, 1969, 18, 23).

La AICT indica claramente que para lograr esta misión, el Estado nacional debe ser considerado como el mayor mal: en 1971, James Becker, miembro del Comité Asesor de AICT, dijo a numerosos maestros y miembros de organismos administradores de la cultura europea que el Estado nacional no sólo había sido uno de los mayores enemigos de la paz mundial en el pasado, sino que seguía representando el mayor peligro potencial en el mundo de aquel entonces, y que incluso debería ser considerado como una entidad agresiva, que podría sumir al mundo en la anarquía en cualquier momento, como se podía observar en las naciones contemporáneas del "tercer mundo." Por lo tanto, Becker propuso considerar la instauración de un gobierno mundial como una manera de prevenir la ocurrencia de este tipo de anarquía. Como era de esperar, la propuesta de Becker de abolir el Estado-nación encontró duras críticas (AICT, 1971, 10, 11). Sin embargo, la idea de un gobierno mundial o de un centro para la planificación mundial ya estaba ampliamente difundida a esas alturas y había encontrado gran apoyo tanto en los EE.UU. como en Europa. Desde el futurista e ingeniero estadounidense Buckminster Fuller hasta el escritor suizo Denis de Rougemont, participante en el Congreso para la Libertad Cultural, de inspiración anticomunista, pasando por el educador alemán Georg Picht, los actores de todo el mundo que participaron en la reforma de la educación y formación docente abogaron por la creación de una estructura supranacional de organización que fuera mucho más allá de las Naciones Unidas, idea en una etapa de desarrollo evidentemente "embrionaria" (Rohstock, 2012; Picht, 1993; Rougemont, 1971).

Estas visiones de un orden mundial unificado contenían una promesa cuasi-religiosa de salvación, que indicaba que el hombre puede lograr "el control sobre su destino" a través de las escuelas y la educación (documento del Senado de EE.UU., citado por AICT, 1971, 13). El trabajo de los profesores ya no se relacionaba con el presente, y desde luego tampoco con el pasado, sino con el futuro: por sobre todo lo demás, los maestros debían preparar a los niños para el mundo del mañana. Esto significaba explícitamente descartar su propio pasado (es decir, el aprendizaje "para descartar nuestros ayeres") (ibid.) junto con el "sacrificio" de las "vacas sagradas" de la formación docente, y en especial la "historia de la educación", como un informe de la UNESCO lo estableció literalmente (Cohen, 1973, 24). Esta intención también puede inferirse del hecho de que la historia nacional comenzó a tener un papel cada vez menos importante en los programas de formación del profesorado a partir de la década de 1970 (Simola, 1998). Los títulos de los programas de formación docente diseñados en la década de 1980 decían mucho al respecto: en 1986, un grupo de trabajo de la Corporación Carnegie publicó su informe, "Una nación preparada: Personal docente para el Siglo XXI." El mismo año, el Grupo Holmes presentó su informe, "Los maestros del mañana" (1986).

Los científicos y los políticos que participaban en la formación del profesorado no sólo querían transformar su contenido, sino que también revolucionar los métodos y 
las técnicas que los profesores utilizaban. Tras el fracaso generalizado de las reformas curriculares que se habían centrado en el desarrollo de tecnologías para el aula y en los propios estudiantes (Dow, 1991; Rohstock, 2012), la psicología cognitiva ejerció una enorme influencia, que se centró cada vez más en la formación docente a partir de la década de 1980 (Popkewitz, 1993). Su rol en esta área de la educación ha sido celebrado, sobre todo, como un proceso de cientifización, como la "aplicación de los conocimientos científicos acerca de la enseñanza" (Marilyn Cochran-Smith, y otros, 2008, 1140; Husén y Postlethwaite, 1985). Ya sea en forma de microenseñanza (Klinzing, 2002), de "instrucción guiada cognitivamente" (Fennema, Carpenter, \& Peterson, 1989; Lüders, 2010), de enfoques experto-novato, o de estrategias metacognitivas en una práctica docente reflexiva (Cruickshank, 1987; Pickle, 1985; Shulman, 1986; Bromme y Haag, 2008), la literatura de investigación sobre la cognición de los docentes ha experimentado un auge sin precedentes desde la década de 1980 (Brommer, 1992; Valli, 1992). Los propios investigadores indicaban claramente que el asunto, quizá primario, en este caso era asegurar los recursos para continuar con la investigación: "Necesitamos apoyo federal continuo para la investigación cognitiva centrada en las cuestiones importantes en torno a (...) la formación del profesorado." Esto debido a que, como explicaban: "nuestra experiencia en la psicología cognitiva es un recurso nacional" (Linn, 1982, 6). Incluso Jerome Bruner debió admitir que, en este sentido, la psicología cognitiva estaba "llena de jugadas inteligentes", especialmente cuando se trataba de auto promoverse como un programa científico que tendría un impacto directo en la práctica social de la educación. "El truco básico era expresar los hallazgos en centímetros, gramos y segundos", dijo Bruner, desenmascarando la supuesta cientifización de la psicología como un simple cambio de énfasis en la cuantificación de los resultados de la propia investigación (Bruner, 1983, 107).

Motivados por el atractivo de un plan de estudios supuestamente riguroso, científico y objetivo, los políticos rápidamente saltaron a bordo. Los informes del Grupo Holmes y el grupo de trabajo Carnegie en los Estados Unidos, "se basaron de manera significativa en la teoría y en la investigación reciente sobre la psicología del aprendizaje y de la enseñanza para describir al profesor ideal" (Peterson, Clark \& Dickinson, 1989 , 2). En consonancia con el objetivo de la cientifización, el maestro ideal tenía que ser, ante todo, un profesor-investigador con un amplio repertorio de ideas y de estrategias para la resolución de problemas. Basándose en sus capacidades metacognitivas, el profesor debía ser capaz de reflexionar sobre sus inferencias y sus acciones y someterse a una especie de proceso de auto-monitoreo con el fin de poder ayudar a los estudiantes a desarrollar "estructuras significativas y coherentes de conocimiento y acción.” Esta, al menos, era la manera como la Asociación Americana de Psicología, a petición del gobierno estadounidense durante la década de 1990, describió los beneficios derivados de su "investigación acerca de la práctica pedagógica durante las últimas décadas" (Baer, 2000, 23).

Desde los Estados Unidos, la psicología cognitiva ha experimentado una verdadera marcha triunfal en relación con la reforma de la formación docente en muchos países occidentales a partir de la década de 1980 (Hudson y Zgaga, 2008). En Alemania, Francia e Inglaterra, por ejemplo, podemos observar que enfoques muy similares a 
la formación del profesorado entraron en vigencia durante la década de 1990. La formación del profesorado se ha dirigido principalmente hacia la profesionalización y la certifización, la mejora de la autonomía docente y la didáctica de las asignaturas, además de un mayor énfasis en el aprendizaje permanente (Nigel 1995). Un estudio de la OCDE sobre este tema en 2010 llegó a la conclusión de que los esfuerzos de reforma inspirados en la psicología cognitiva que habían tenido lugar en los estados miembros de la OCDE habían elevado a los educadores al nivel de "expertos en su campo específico ... con un fuerte sentido crítico, autonomía y capacidades profesionales para la resolución de problemas"(Musset, 2010, 5).

\section{Cambio de guardia: De los mecanismos de control externos hacia los internos en la enseñanza de docentes}

La transformación de los temas recurrentes en la formación del profesorado que tuvo lugar a partir del siglo XIX hacia el siglo XXI (como se describe en los dos capítulos anteriores) se puede resumir de la siguiente manera: Por un lado, se observa un cambio en el contexto geográfico e ideológico en el que la formación de docentes ha tenido lugar en los últimos 150 años. Si bien el punto central de atención durante el siglo XIX fue el Estado-nación y, por extensión, la educación de los ciudadanos, desde el comienzo del siglo XX este enfoque ha sido sustituido progresivamente por un ideal cada vez más orientado a un contexto internacional.

En segundo lugar, se ha producido un cambio normativo perceptible desde narrativas morales y religiosas hacia discursos científicos y racionalistas. Considerando que la educación de los jóvenes estudiantes en el siglo XIX se llevó a cabo con un celo emotivo e incluso misional, desde el rápido ascenso del paradigma de cientifización durante el período entre guerras, los métodos de enseñanza se han aparejado con un ideal que es precisamente lo contrario: el profesor no debe aparecer como un moralizador religioso, sino que debe actuar de acuerdo con criterios estrictamente racionales y científicos. No es muy reconocido el hecho de que este "racionalismo de esperanzas" también tiene un elemento fundamentalmente religioso (Simola, 1993).

En tercer lugar, parece que hay un cambio permanente en los puntos de referencia temporal. En el siglo XX, los expertos con influencia internacional fueron explícitos acerca de comprometer sus esfuerzos para "asesinar" a la que todavía era una vaca sagrada en el siglo XIX: La historia de la educación. Trataron de eliminar las referencias al pasado en la formación docente y sustituirlas por referencias al futuro, un momento en el que un mundo unificado por la normalización en la educación y la ciencia podía prometer resolver los problemas cada vez más interdependientes de un mundo globalizado.

En cuarto lugar, este cambio también significó el alejamiento de un canon educativo fijo hacia un concepto cada vez más constructivista del conocimiento. Como consecuencia del ideal constructivista, las estructuras cognitivas y las habilidades para resolver problemas abstractos, matemáticos y lógicos pasaron a un lugar de privilegio por sobre el conocimiento del mundo ligado a lo histórico y a lo cultural. El contenido había sido "asimilado como nociones abstractas y generales" (Simola, 1998, 345). 
Tan fundamental como pudo ser el cambio de la formación docente entre los siglos XIX y XXI en el nivel discursivo y de las ideas de los leitmotivs y los planes para la reforma de políticas, la implementación de estos cambios en el nivel de la práctica en el aula de enseñanza es algo totalmente diferente. Por un lado, hay grandes interrogantes acerca de la manera en que este enfoque internacional de los programas de formación de profesores en realidad se abrió paso hacia la enseñanza cotidiana y si realmente lo consiguió. Una investigación publicada recientemente encontró que a pesar de toda la retórica de la europeización y la internacionalización, el punto de referencia más habitual en la práctica docente real a lo largo de una variedad de materias escolares sigue siendo el Estado-nación (para Europa, ver Schleicher \& Weber, 2002).

Por otro lado, se ha demostrado que el antropocentrismo orientado a la razón presente en la psicología cognitiva es muy difícil de impartir a los estudiantes en la práctica en el aula real. Los proyectos curriculares de la década de 1960, por ejemplo-en los cuales a los estudiantes se les pedía encontrar respuestas a preguntas tales como: “¿qué es lo exclusivamente humano de los seres humanos?”; “¡cómo los seres humanos llegaron a ser así?”; o “¿qué se podría hacer para que tendieran aún más a ser de esa manera?” (Bruner, 1983) — fallaron en la labor de obtener resultados positivos, sin excepciones (Dow, 1991).

Por otra parte, todavía no podemos predecir si las reformas en la formación docente de acuerdo con las premisas de la psicología cognitiva en realidad se pueden aplicar de manera tan universal como sugiere el discurso de la cientifización y como los políticos lo han propagado; a este respecto, basta recordar la creencia generalizada en la transposición, sin inconvenientes, de modelos supuestamente probados y de "mejores prácticas" a contextos culturales diferentes. El grado en que la psicología cognitiva ha sido y es esencialmente occidental, orientada a lo masculino y racionalista - y por tanto culturalmente contextualizada — nunca se expresa más claramente que en las posiciones adoptadas por quienes la proponen. Por ejemplo, Jerome Bruner caracteriza el concepto de inteligencia emocional como "una idea absurda sin duda" (Orlofsky, 2001, 68). El hecho de que todo este modo de pensar estaba condicionado por diferenciaciones jerárquicas que privilegian a una cultura racionalista y occidental quedó evidenciado en la caracterización que Bruner hizo acerca de los niños inmigrantes latinoamericanos; "las diferentes culturas producen diferentes tipos de mentes", fue la explicación lapidaria para su falta de éxito en el sistema escolar de Estados Unidos (Bruner citado por Olson, 2007, 23). Bruner pasó a pontificar sobre las enormes posibilidades que ofrece el sistema educativo como un instrumento de reproducción cultural. En su opinión, "la educación en un sentido formal, [era] el medio principal o el más poderoso para transmitir o recrear la cultura” (Bruner, 1983, 178). Seguirá siendo una especulación si opiniones de este tipo fueron consideradas por las autoridades estadounidenses principalmente en el contexto de la Guerra Fría. Sin embargo, especialmente en el contexto de la confrontación entre el bloque oriental y el occidental, no se puede descartar que la psicología cognitiva, bajo la bandera no ideológica de una cientifización de aplicación universal, fuera utilizada por los políticos para reproducir la cultura escolar occidental y estadounidense. 
Al final, el elemento cuasi-religioso, particularmente como se manifestó en la retórica de la salvación de numerosos políticos y de organizaciones internacionales, jugó un papel mucho mayor que el que la narrativa de la cientifización de la formación docente sugeriría a primera vista. La religiosidad había disfrutado de un impulso particularmente significativo en el ambiente anti-comunista de la era McCarthy (Rudolph, 2002). Como resultado, el ideal estadounidense de la educación, que siempre se había asociado con el protestantismo, se aferró con mayor firmeza a sus raíces religiosas, aunque con un nuevo giro. Por paradójico que pueda parecer, en el contexto de la Guerra Fría, el pensamiento acerca de la salvación religiosa que fue parte de una filosofía educativa estadounidense marcada por el protestantismo se amalgamó con la ideología cientificista de la élite académica, generando una especie de creencia mundial en la salvación a través de la educación científica (Rohstock, 2012). Su carácter calvinista distintivo posteriormente se enfrentó con la otra denominación fuerte de origen protestante, el luteranismo, en un choque que se manifiesta con mayor fuerza en Alemania en el contexto de PISA (Tröhler, 2011).

Por último, pero no menos importante, también deberíamos ser escépticos sobre la retórica de la autonomía. Los políticos de todo el mundo suelen vincular los enfoques cognitivos en la formación docente con la mejora de las libertades individuales. John M. Heffron, que en ese momento trabajaba como profesor asistente en la Universidad de Hawaii en Manoa, argumentó en oposición a esta idea. En un ensayo muy bien argumentado, escribió que los préstamos históricamente documentados de la cibernética, los que la psicología cognitiva había tomado en el curso de su desarrollo, sólo habían dado lugar a un cambio en los mecanismos de control educativo desde una fuente externa a una ubicación interna. De esta manera, no tenía sentido hablar de ningún aumento en la autonomía, en el sentido de la libertad (Heffron, 1995). Con respecto a la formación docente, podemos confirmar que tal cambio de fuentes de control externas a internas efectivamente ocurrió. Es decir, el control del gobierno y de los instrumentos de planificación en los siglos XIX y XX dio paso a la internalización individual de los mecanismos de control en el siglo XIX, un cambio que, en última instancia, garantiza mucho más control total sobre todo el sistema. Como un servomecanismo que opera sobre una retroalimentación sin fin, el maestro, ahora equipado con habilidades metacognitivas, podría observar, controlar y, si es necesario, ajustar constantemente su actividad en un ciclo de optimización auto-referencial y auto-reflexivo. Es incuestionable que los defensores de la revolución cognitiva en la década de 1960 ya veían esto como un paso hacia el perfeccionamiento deseado de la mente humana. De hecho, Jerome Bruner destacó el "efecto liberador" que el computador ejercería de manera ostensible sobre las concepciones de los psicólogos acerca de lo que era humanamente posible (Bruner, 1983, 104). Aún queda por ver si la "liberación" es un término adecuado para un sistema de control que funciona de manera intrínseca, precisamente porque es interno y no impuesto desde el exterior, y funciona como una condición de la existencia humana potencialmente imposible de contrarrestar. 


\section{Notas}

1. El material presentado en las siguientes sub-secciones fue incluido previamente en Tröhler, 2006.

2. En este trabajo solamente se incluyeron los nombres de las personas listadas en la tabla de contenidos, dado que se consideró que tal inclusión en un listado demuestra la importancia que se asigna a dicha persona. Con esto se evita el efecto engañoso de la mención superficial dentro del texto.

3. No obstante, se debe notar en la historiografía francesa la manera en que valida los discursos ingleses y estadounidenses del siglo XIX, mientras que en Alemania la experiencia con las ideas "extranjeras" del siglo XIX estaba restringida a lo que se conoció como el método Bell-Lancaster.

\section{Referencias}

Anderson, B. (2006). Imagined communities. Nueva edición. Londres: Verso (primera edición, 1983).

The Atlantic Information Centre for Teachers (Ed.). (1968). National stereotypes: an educational challenge. Report of an international seminar for teachers organized at Elsinore, Denmark, by the Atlantic Information Centre for Teachers, 17th to 22nd March 1968. J. Eppstein (Ed.). London, UK: Atlantic Information Center for Teachers.

The Atlantic Information Centre for Teachers (Ed.). (1969). Teaching about the American impact in Europe. Report of an international seminar for teachers organised at Füssen, Germany by the Atlantic Information Centre for Teachers, 23-28 November 1969. J.R. Huntley (Ed.). Reading, UK: Lamport Gilbert Printers.

The Atlantic Information Centre for Teachers (Ed.). (1972a). Teaching about collective security and conflict: report of an international seminar for teachers organised at Rungstedgaard, near Copenhagen, by the Atlantic Information Centre for Teachers, 28-31 October 1971. J.R. Huntley (Ed.). London, UK: Atlantic Educational Publications.

The Atlantic Information Centre for Teachers (Ed.). (1972b). Television and world affairs teaching in schools; Report of the Atlantic Study Conference on Education (9th, Bordeaux, Sept. 3-9, 1972). J. Eppstein (Ed.). London, UK: Atlantic Educational Publications.

Baer, M. (2000). Schulen zu Schulen für Schülerinnen und Schüler weiterentwickeln. En Beiträge zur Lehrerbildung, 18(1), 23-25.

Becker, H. (1980). Aufdem Weg zur lernenden Gesellschaft: Personen, Analysen, Vorschläge für die Zukunft. Stuttgart: Klett-Cotta.

Bell, D. (1960). The End of ideology: On the exhaustion of political ideas in the fifties. Glencoe, IL: Free Press.

Bernhard, P., \& Rohstock, A. (forthcoming 2013). Learning from each other? A transnational history of fascist education in Italy, Spain and Nazi-Germany 1922-1945.

Boden, M. A. (2006). Mind as machine: A history of cognitive science. Dos volúmenes. Oxford, UK: Oxford University Press.

Bölling, R. (1978). Volksschullehrer und Politik. Der deutsche Lehrerverein 1918-1933. Göttingen: Vandenhoeck \& Ruprecht.

Bromme, R. \& Haag, L. (2008). Forschung zur Lehrerpersönlichkeit. En W. Helsper, W J. Böhme (Eds.). Handbuch der Schulforschung (pp. 803-819). Wiesbaden: Verlag für Sozialwissenschaften.

Bromme, R. (1992). Der Lehrer als Experte: Zur Psychologie des professionellen Wissens. Bern: Huber. 
Bruner, J. S. (1960). The process of education. Cambridge, UK: Harvard University Press.

Bruner, J. S. (1980). Jerome S. Bruner. En G. Lindsey (Ed.). History of psychology in autobiography, Vol. 7 (pp. 75-151). San Francisco, CA: W. H. Freeman.

Bruner, J. S. (1983). In search of mind: Essays in autobiography. New York, NY: Harper \& Row.

Bruner, J. S. (2006). In search of pedagogy: the selected works of Jerome S. Bruner, Vol. 1. New York, NY: Routledge.

Butler, N. M. (1912). The International mind: An Argument for the judicial settlement of international disputes. New York, NY: Scribner.

Carnegie Commission Task Force. (1986). A nation prepared: teachers for the 21st century. New York, NY: Carnegie Cooperation.

Chabbott, C. (2003). Constructing education for development: international organizations and education for all. New York, NY: Routledge Falmer.

Cochran-Smith, M., Feiman-Nemser, S., McIntyre, D. J., \& Demers, K. E. (Eds.). (2008). Handbook of research on teacher education. Enduring questions in changing contexts, $3 r d$ Edition. New York, NY: Routledge.

Cohen, D. (Ed.). (1973). New trends in integrated science teaching. Volume IV: Evaluation of integrated science education. París: UNESCO.

Compayré, G. (1879). Histoire critique des doctrines de l'éducation en France depuis le seizième siècle. París: Hachette.

Compayré, G. (1883). Histoire de la pédagogie. Paris: P. Delaplane.

Condette, J.-F. (2007). Histoire de la formation des enseignants en France (XIXe-XXe siècles). Paris: L'Harmattan.

Craig, G. (1978). Germany, 1866-1945. Oxford, UK: Claredon Press.

Cromley, J. (2000). Learning to think, learning to learn: what the science of thinking and learning has to offer adult education. Washington, DC: National Institute for Literacy.

Cruickshank, D. (1987). Reflective teaching. Reston, VA: Association of Teacher Educators.

Dickinson, E. R. (2004). Biopolitics, fascism, democracy: some reflections on our discourse about 'modernity". En Central European History, 37(1), 1-48.

Dittes, F. (1871). Geschichte der Erziehung und des Unterrichts: für dt. Volksschullehrer. Leipzig: Klinkhardt.

Dittes, F. (1879). Histoire de l'éducation et de l'instruction. Traduit de l'Allemand par Auguste Redolf. Geneva: Schira-Blanchard.

Dow, P. (1991). Schoolhouse publics: Lessons from the Sputnik era. Cambridge, MA: Harvard University Press.

Drewek, P. (2002). "Defensive Disziplinbildung_Die Akademisierung der deutschen Pädagogik im Kontext der Modernisierungsprobleme des Bildungssystems und der Erziehungswissenschaft am Beginn des 20. Jahrhunderts.” En R. Hofstetter \& B. Schneuwly (Ed.). Erziehungswissenschaft(en) 19.-20. Jahrhundert. Zwischen Profession und Disziplin (pp. 113-140). Bern, Berlin, Bruxelles: Lang.

Erickson, P. (2006). The politics of game theory: mathematics and Cold War culture. Madison, WI: University of Wisconsin-Madison.

Etzemüller, T. (2009). Social engineering als Verhaltenslehre des kühlen Kopfes. Eine einleitende Skizze. En T. Etzemüller, (Ed.). Die Ordnung der Moderne. Social Engineering im 20. Jahrhundert (pp. 11-39). Bielefeld: Transcript 2009.

Etzemüller, T. (2010). Social Engineering. En Docupedia-Zeitgeschichte. Begriffe, Methoden und Debatten der zeithistorischen Forschung. [On-line]. Disponible: http://docupedia.de/ zg/Social_engineering

Fennema, E., Carpenter, T. P., \& Peterson, P. (1989). Teachers' decision making and cognitively guided instruction: a new paradigm for curriculum development. En N. F. Ellerton \& M. A. Clements. School mathematics: The Challenge to change, (pp. 174-87). Geelong, Victoria, Australia.: Deakin University Press. 
Fichte, J. G. (2008). Addresses to the German nation (1808). Cambridge, UK: Cambridge University Press.

Fuchs, E., Lindmark, D., \& Lüth, C. (Eds.). (2006). Transnational networks in history of education, Paedagogica Historica.

Fuchs, E. (2006). Kinderschutz und Völkerbund. Zur Formierung des edukativen Multikulturalismus in der Zwischenkriegszeit. En E. Fuchs (Ed.). Bildung international. Historische Perspektiven und aktuelle Entwicklungen (pp. 163-180). Würzburg: Ergon-Verlag.

Führ, C. (1989). Schulen und Hochschulen in der Bundesrepublik Deutschland. Bildungspolitik und Bildungssystem. Ein Überblick. Köln: Böhlau.

Goodlad, J. (1966). The changing school curriculum. New York, NY: Fund for the Advancement of Education.

Hartman, A. (2008). Education and the Cold War: the battle for the American school. New York, NY: Palgrave Macmillan.

Heffron, J. M. (1995). Toward a cybernetic pedagogy: the cognitive revolution and the classroom, 1948-present. Educational Theory, 45(5), 497-518.

Hofstetter, R. et al. (2009). Une formation professionnelle universitaire pour tous les enseignants. L'exemple de la Suisse au xxe siècle. Recherche \& formation, 1(60), 25-38.

The Holmes Group. (1986). Tomorrow's teachers: A report of the Holmes Group. Michigan, MI: The Holmes Group.

Hopmann, S. T. (2008). Lehrer/innenbildung in internationaler Perspektive. Journal für LehrerInnenbildung. Schnittstelle Lehrerbildung und Schule im internationalen Kontext, 3(8). Jahrgang, 6-13.

Hudson, B. \& Zgaga, P. (Eds.). (2008). Teacher education policy in Europe: a voice of higher education institutions. Ljubljana: Littera picta.

Husén, T. \& Postlethwaite, N. (1985). International encyclopedia of education. Oxford, UK: Pergamon Press.

Issaurat, C. (1886). La pédagogie. Son évolution et son histoire. París: C. Reinwald.

Kehrein, J. (1887 [1873]). Überblick der Geschichte der Erziehung und des Unterrichts: für Zöglinge der Lehrerseminare und zur Vorbereitung auf die Allg[emeinen] Bestimmungen angeordnete Prüfungen. Paderborn: Schöningh.

Kellner, L. (1872). Kurze Geschichte der Erziehung und des Unterrichtes mit verwaltender Rücksicht auf das Volksschulwesen. Freiburg/Breisgau: Herder.

Klinzing, H. G. (2002). Wie effektiv ist Microteaching? Zeitschrift für Pädagogik 48, 194-21.

Kuehl, W. F., \& Dunn, L. (1997). Keeping the covenant: American internationalists and the League of Nations. Kent, OH: The Kent State University Press.

Kuhn, T.S. (1962). The Structure of scientific revolutions. Chicago, IL: University of Chicago Press.

Labaree, D. (2008). An Uneasy Relationship: The History of Teacher Education in the University. En M. Cochran-Smith, S. Feiman Nemser, \& J. McIntyre (Eds.). Handbook of research on teacher education: Enduring issues in changing contexts (3rd ed.) (pp. 290306). Washington, DC: Association of Teacher Educators.

Lagemann, E. C. (2000). An elusive science. The troubling history of education research. Chicago, IL: University of Chicago Press.

Leslie, S. W. (1993). Cold War and American science: the military-industrial-academic complex at MIT and Stanford. New York, NY: Columbia University Press.

Linn, M. C. (1982). The importance of cognitive psychology in curriculum development and teacher education. Documento presentado durante la visita de la Comisión Nacional para la Excelencia en Educación al Lawrence Hall of Science, Universidad de California (Berkeley, CA). 
Lüders, M. (2010). Methodentraining in der Lehrerbildung und Lehrerfortbildung. Grundriss eines Programms für „effektives Unterrichten. En F.H. Müller, A. Eichenberger, M. Lüders, \& J. Mayr, (Eds.). Lehrerinnen und Lehrer lernen: Konzepte und Befunde zur Lehrerfortbildung (pp. 345-357). Münster: Waxmann.

McDougall, W. A. (1985). ...the Heavens and the earth: A Political history of the space age. New York, NY: Johns Hopkins University Press.

Miller, G. A. (2003). The cognitive revolution: a historical perspective. TRENDS in Cognitive Sciences, 7(3), 141-144.

Müller-Rolli, S. (1989). Lehrer. En D. Langewiesche, \& H.-E. Tenorth (Eds.). Handbuch der deutschen Bildungsgeschichte. Vol 5: 1918-1945. Die Weimarer Republik und die nationalsozialistische Diktatur (pp. 240-258). Munich: Beck.

Musset, P. (2010). Initial teacher education and continuing training policies in a comparative perspective: Current practices in OECD countries and a literature review on potential effects. Documentos de Trabajo sobre Educación OECD, (48), OECD Publishing. [Online]. Disponible: http://dx.doi.org/10.1787/5kmbphh7s47h-en

Nelles, W. C. (1995). From Imperialism to internationalism in British Columbia education and society, 1900 to 1939. (Inédito tesis doctoral). Department of Social and Educational Studies, University of British Columbia, Canadá.

Nigel, N. (1995). Initial teacher education in France, Germany, and England and Wales: A Comparative perspective. Compare, 25(3), 211-226.

OECD. (1971a). Training, recruitment and utilization of teachers in primary and secondary education. París: OECD.

OECD. (1971b). Teaching resources and structural change. Conference on policies for educational growth, Paris, 3rd-5th June, Vol. 5. París: OECD.

OECD. (1974a). The teacher and educational change: a new role. Vol. 1: General report. París: OECD.

OECD. (1974b). The teacher and educational change. Vol 2: Recent trends in teacher recruitment. París: OECD.

OECD. (1977). Activities of OECD in 1976. Informe del Secretario General. París: OECD.

Olson, D. (2007). Jerome Bruner. The Cognitive revolution in educational theorye. New York, NY: Continuum International Publishing.

Orlofsky, D. (2001). Redefining teacher education. The Theories of Jerome Bruner and the practice of training teachers. New York, NY: Peter Lang.

Peterson, P. L., Clark, C. M., \& Dickson, P. W. (1989). Educational psychology as a "foundation" in teacher education: Reforming an old notion. Documento 89-9 del Centro Nacional para la Investigación sobre el Aprendizaje Docente, Escuela de Educación, Michigan State University. [On-line]. Disponible: (http://ncrtl.msu.edu/issue.htm)

Picht, G. (1993). Geschichte und Gegenwart: Vorlesungen zur Philosophie der Geschichte, Vol. 9. Stuttgart: Klett-Cotta.

Pickle, J. (1985). Toward teacher maturity. Journal of Teacher Education, 36(4), 55-59.

Popkewitz, T. S. (1993). Changing patterns of power: Social regulation and teacher education reform. Albany, NY: SUNY Press.

Ravitch, D. (2002). A Brief history of teacher professionalism. [On-line]. Disponible: http:// www.udel.edu/educ/whitson/897s05/files/ravitch_Teacher_Professionalism.htm

Razik, T. A. (1972). Systems approach to teacher training and curriculum development: the Case of developing countries. París: UNESCO, Instituto Internacional para la Planificación Educativa.

Rohstock, A. (forthcoming 2012). Antikörper zur Atombombe. Verwissenschaftlichung und Programmierung des Klassenzimmers im Kalten Krieg. En P. Bernhard, \& H. Nehring (Eds.). Den Kalten Krieg denken. Beiträge zur sozialen Ideengeschichte seit 1945. Essen: Klartext. 
Rougemont, D. (1971). Res Publica Europeenne. The Atlantic Community Quarterly, 9(2), 235-242.

Rousselot, P. (1891). Pédagogie historique d'après le principaux pédagogues, philosophes et moralistes. París: C. Delagrave.

Rudolph, J. (2002). Scientists in the classroom. The Cold War reconstruction of American science education. New York, NY: Palgrave Macmillan.

Sandfuchs, U. (1978). Universitäre Lehrerausbildung in der Weimarer Republik und im Dritten Reich. Bad Heibrunn: Klinkhardt.

Schellack, A. \& Große, S. (Eds.). (2007). Bildungswege: Aufgaben für die Wissenschaft-Herausforderungen für die Politik. Münster: Waxmann.

Schleicher, K. \& Weber, P. (Eds.). (2002). Zeitgeschichte europäischer Bildung 1970-2000. Vol. 3: Europa in den Schulen. Münster: Waxmann.

Schorn, A. (1873). Geschichte der Pädagogik, in Vorbildern und Bildern. Leipzig: Dürr.

Shulman, L. S. (1986). Those who understand: knowledge growth in teaching. Educational Researcher, 15(2), 4-14.

Simola, H. (1992). "El camino al infierno está lleno de buenas intenciones." Discurso sobre educación de docentes, en Informes del Comité Finlandés entre 1922 y 1991. Trabajo presentado en AARE/NZARE Simposio de la Conferencia conjunta para la Reforma Educacional. Deakin University, Geelong, Australia 22-26 Noviembre, 1992; [On-line]. Disponible: http://www.aare.edu.au/92pap/simoh92322.txt

Simola, H. (1993). Professionalism and rationalism of hopes: outlining a theoretical approach for a study on educational discourse. International Studies in Sociology of Education, 3(2), 173-192.

Simola, H. (1998). Constructing a school-free pedagogy: decontextualization of Finnish state educational discourse. Curriculum Studies, 30(3), 339-356.

Skinner, B. F. (1948). Walden two. Indianapolis, IN: Hackett Publishing Company.

Stewart, I. (1980). Organizing scientific research for war. New York, NY: Arno Press.

Tanner, D., \& Tanner, L. (1987). Supervision in education: Problems and practices. New York, NY: Macmillan.

Thomas, J. B. (1990). British universities and teacher education: A Century of change. London, UK: Falmer Press.

Tröhler, D., Popkewitz, T. S., \& Labaree, D. (2011). Schooling and the making of citizens in the long nineteenth century. New York, NY: Palgrave Macmillan.

Tröhler, D. (2006). The Formation and Function of Histories of Education in Continental Teacher Education Curricula. Journal of the American Association for the Advancement of Curriculum Studies 2, 0-17. [On-line]. Disponible: http://www.uwstout.edu/soe/jaaacs/ vol2/trohler.htm

Tröhler, D. (2010). Harmonizing the educational globe. World polity, cultural features, and the challenges to educational research. Studies in Philosophy and Education, 29(1), 7-29.

Tröhler, D. (2011). Concepts, cultures, and comparisons: PISA and the double German discontentment. En D. Tröhler, Languages of education: Protestant legacies, national identities, and global aspirations (pp. 194-207). New York, NY: Routledge.

Tyack, D. B. (Ed.). (1967). Turning points in American educational history. Waltham, MA: Blaisdell Publishing Company.

Valli, L. (1992). Reflective teacher education. Cases and critiques. Albany, NY: State University of New York Press.

Vincent, P. (1885). Histoire de la pédagogie. París: F. Nathan.

Weimarer Reichsverfassung (Verfassung des Deutschen Reiches). (1919). [On-line]. Disponible: http://www.documentarchiv.de/wr/wrv.html

Witry, T. (1900). Statistique historique du Grand-Duché de Luxembourg: La situation de l'enseignement primaire dans le Grand-Duché de Luxembourg pendant la période de 1815 à 1900. Luxemburg: V. Buck. 
World Federation of Education Associations. (1929). Proceedings of the third biennial conference held in Geneva, Switzerland, from July 29th to August 4th 1929. Geneva.

Yates, A. (1970). Current problems of teacher education: Report of a meeting of international experts. París: Instituto para la Educación de la UNESCO. 